University of Nebraska - Lincoln

DigitalCommons@University of Nebraska - Lincoln

\title{
Application of hyperspectral vegetation indices to detect variations in high leaf area index temperate shrub thicket canopies
}

\author{
Steven T. Brantley \\ Virginia Commonwealth University, brantleyst@vcu.edu \\ Julie C. Zinnert \\ US Army ERDC Fluorescence Spectroscopy Lab \\ Donald R. Young \\ Virginia Commonwealth University
}

Follow this and additional works at: https://digitalcommons.unl.edu/usarmyresearch

Part of the Operations Research, Systems Engineering and Industrial Engineering Commons

Brantley, Steven T.; Zinnert, Julie C.; and Young, Donald R., "Application of hyperspectral vegetation indices to detect variations in high leaf area index temperate shrub thicket canopies" (2011). US Army Research. 114.

https://digitalcommons.unl.edu/usarmyresearch/114

This Article is brought to you for free and open access by the U.S. Department of Defense at DigitalCommons@University of Nebraska - Lincoln. It has been accepted for inclusion in US Army Research by an authorized administrator of DigitalCommons@University of Nebraska - Lincoln. 


\title{
Application of hyperspectral vegetation indices to detect variations in high leaf area index temperate shrub thicket canopies
}

\author{
Steven T. Brantley ${ }^{\mathrm{a}, *}$, Julie C. Zinnert ${ }^{\mathrm{b}, 1}$, Donald R. Young ${ }^{\mathrm{a}}$ \\ a Department of Biology, Virginia Commonwealth University, Richmond, Virginia 23284, United States \\ ${ }^{\mathrm{b}}$ US Army ERDC Fluorescence Spectroscopy Lab, 7701 Telegraph Road Alexandria, VA 22315, United States
}

\section{A R T I C L E I N F O}

Article history:

Received 22 March 2010

Received in revised form 28 September 2010 Accepted 29 September 2010

\section{Keywords:}

Canopy architecture

Canopy chlorophyll

Plant stress detection

Elaeagnus umbellata

Morella cerifera

Woody encroachment

\begin{abstract}
A B S T R A C T
Accurate measurement of leaf area index (LAI), an important characteristic of plant canopies directly linked to primary production, is essential for monitoring changes in ecosystem $C$ stocks and other ecosystem level fluxes. Direct measurement of LAI is labor intensive, impractical at large scales and does not capture seasonal or annual variations in canopy biomass. The need to monitor canopy related fluxes across landscapes makes remote sensing an attractive technique for estimating LAI. Many vegetation indices, such as Normalized Difference Vegetation Index (NDVI), tend to saturate at LAI levels $>4$ although tropical and temperate forested ecosystems often exceed that threshold. Using two monospecific shrub thickets as model systems, we evaluated the potential of a variety of algorithms specifically developed to improve accuracy of LAI estimates in canopies where LAI exceeds saturation levels for other indices. We also tested the potential of indices developed to detect variations in canopy chlorophyll to estimate LAI because of the direct relationship between total canopy chlorophyll content and LAI. Indices were evaluated based on data from direct (litterfall) and indirect measurements (LAI-2000) of LAI. Relationships between results of direct and indirect ground-sampling techniques were also evaluated. For these two canopies, the indices that showed the highest potential to accurately differentiate LAI values $>4$ were derivative indices based on red-edge spectral reflectance. Algorithms intended to improve accuracy at high LAI values in agricultural systems were insensitive when LAI exceeded 4 and offered little or no improvement over NDVI. Furthermore, indirect ground-sampling techniques often used to evaluate the potential of vegetation indices also saturate when LAI exceeds 4. Comparisons between hyperspectral vegetation indices and a saturated LAI value from indirect measurement may overestimate accuracy and sensitivity of some vegetation indices in high LAI communities. We recommend verification of indirect measurements of LAI with direct destructive sampling or litterfall collection, particularly in canopies with high LAI.
\end{abstract}

(c) 2010 Elsevier Inc. All rights reserved.

\section{Introduction}

Leaf area index (LAI) is a key structural characteristic of plant canopies that directly affects rates of atmospheric gas exchange, absorption of solar radiation, and interception of meteorological nutrients (Bonan, 1993; Runyon et al., 1994). Because of a fundamental importance to ecosystem processes, accurate estimation of LAI is necessary for monitoring changes in ecosystem C stocks (SanchezAzofeifa et al., 2009). Collection and analysis of leaf litterfall biomass and a dry weight/leaf area conversion factor can provide an accurate and direct physical measurement of LAI (Brantley \& Young, 2007; Gower et al., 1999; Newbold, 1967). While direct measurement of LAI is most accurate, techniques such as litter collection, or alternatives such as direct destructive sampling or allometry, that rely on harvest of leaf biomass are labor intensive and do not reflect seasonal or

\footnotetext{
* Corresponding author.

E-mail address: brantleyst@vcu.edu (S.T. Brantley).

1 Julie C. Zinnert was formerly Julie C. Naumann.
}

interannual variations unless repeated for each period of interest. Indirect methods of estimating LAI, such as hemispheric photography, portable integrating radiometry and light attenuation, either lose sensitivity at high LAI values or require a priori knowledge of canopy structure to determine an extinction coefficient (Brantley \& Young, 2007). At the landscape scale, analysis of aerial and/or satellite imagery is a practical approach for rapid estimation of LAI across populations, communities and ecosystems. Remote sensing of vegetation has the added advantage of providing biophysical measurements for landscapes with limited access. Perhaps most importantly, remote-sensing methods are repeatable seasonally and/ or annually with relatively little labor enhancing the ability to quantify temporal changes in LAI, ANPP (annual net primary production), biomass and related phenomena.

For the past two decades, the normalized difference vegetation index (NDVI) has been the standard algorithm used to quantify and map spatial distribution of green vegetation with the aim of estimating ANPP and other landscape-level fluxes. NDVI is based on differences in reflectance in the red region (due to pigment absorption) and maximum 
reflectance in the near-infrared (caused by leaf cellular structure; Table 1) and is sensitive to canopy greenness. Like indirect methods of ground-sampling, NDVI loses sensitivity as LAI values increase and NDVI and related algorithms often reach saturation at LAI values of 3-4 (Asner et al., 2000). Because NDVI saturates easily, derived LAI values are often static, insensitive to small spatial and temporal variations across landscapes and are poor indicators of canopy physiology (Grace et al., 2007; Haboudane et al., 2004; Turner et al., 2004; Wang et al., 2005). A lack of sensitivity at high LAI values is of little consequence in most arid and many temperate ecosystems, but can lead to severe underestimation of LAI and related ecological fluxes in highly productive systems. Tropical, sub-tropical and other systems with high ANPP have the greatest potential for $\mathrm{C}$ sequestration and finding solutions to this paradox is an ongoing issue in the application of vegetation remote sensing (Asner et al., 2000; Grace et al., 2007; Sanchez-Azofeifa et al., 2009; Turner et al., 2004).

Remotely sensed hyperspectral images of tropical forests have been used effectively to estimate changes in vegetative biophysical chemistry and understand basic ecological properties (Asner, 2000). Vegetation indices that incorporate bands in the green and red-edge region and that are good predictors of LAI include the modified chlorophyll absorption ratio index (MCARI; Table 1) and the triangular vegetation index (TVI; Table 1). Similar to NDVI, many reflectance indices developed for ANPP estimation have been unsuccessful at fine scale dynamic changes because they also approach a saturation level asymptotically as LAI increases. These indices are also sensitive to the effects of chlorophyll absorptions. Several indices were developed by Haboudane et al. (2004) as modified versions of MCARI and TVI, and these were expected to be less sensitive to chlorophyll effects and more responsive to variations in green LAI. These indices include MCARI1, MCARI2 (which incorporates a soil adjustment factor) and MTVI2 (modified TVI; Table 1) and MCARI2 and MTVI2 were demonstrated to accurately predict LAI in modeled crop canopies (Haboudane et al., 2004). Although these algorithms were specifically developed for agricultural applications, application to natural ecosystems has potential to improve estimates of LAI and further aide in providing accurate estimates of ANPP and C cycling.

An additional group of vegetation indices that show promise in improving LAI estimation in high LAI canopies are based on changes in red edge spectral reflectance. The red-edge region is characterized as a sharp change in reflectance between wavelengths at $690-750 \mathrm{~nm}$. This area is the boundary between dominance by absorption of red light and high scattering of radiation in the mesophyll (Curran et al., 1990; Horler et al., 1983). Although typically used for stress detection, these algorithms may also be strongly influenced by increases in LAI due to enhanced cellular scattering of leaves. Examples of these indices include $D_{730} / D_{706}$ and $R_{740} / R_{850}$ (Zarco-Tejada et al., 2002,
2009; Zhang et al., 2008). Other red-edge reflectance and derivative indices associated with changes in LAI include $R_{761} / R_{757}, R_{750} / R_{710}$, $\mathrm{D}_{705} / \mathrm{D}_{722}, \mathrm{D}_{\max } / \mathrm{D}_{705}, \mathrm{D}_{\max } / \mathrm{D}_{745}$ and $\mathrm{D}_{715} / \mathrm{D}_{705}$ (Campbell et al., 2007; Zarco-Tejada et al., 2009; Zhang et al., 2008). A related index, the chlorophyll index $(\mathrm{CI})$, also uses red-edge wavelengths and is a good predictor of chlorophyll content in high LAI systems and, given homogenous chlorophyll values, LAI is inherently linked to total canopy chlorophyll content as represented in reflectance data (Gitelson et al., 2005; Zhang et al., 2008).

In addition to the direct influences of LAI on red-edge indices, there may be a second less direct link between LAI and canopy reflectance. Slight variations in biomass may also be reflected in remotely sensed vegetative stress indices because variations in canopy physiology and biochemistry caused by environmental stress often affect plant productivity (i.e. plants under stress often display lower LAI values). For instance, Asner et al. (2004) showed that in humid tropical forests with high LAI $(>5)$, canopy leaf area was sensitive to water stress reflectance metrics. In systems with high environmental gradients and variability of stressors, LAI is likely to be strongly related to spatial variations in environmental stress and this covariation between LAI and stress may confound LAI estimation or it may provide a potential surrogate measure of canopy biomass. As with red-edge reflectance indices, application of stress-related indices incorporating pigment reflectance as a predictor of LAI is emerging as another potential method to improve accuracy of remote sensing in high LAI canopies.

Application of algorithms developed for ecosystems with high LAI and/or NPP is not limited to use in tropical or agricultural systems. Most temperate, mesic systems display LAI values $<6$, but mesic shrub thickets may exhibit LAI values as high as 10-12 (Brantley \& Young, 2007; Knapp et al., 2008). Expansion of native and exotic shrubs into historically herbaceous communities has been observed across a broad range of ecosystems and changes in ecosystem function resulting from woody encroachment are strongly linked to a stimulation in ecosystem LAI which affects hydrology, nutrient cycling, and species diversity (Archer, 1989; Brantley \& Young, 2008; Briggs et al., 2005; Knapp et al., 2008; Sturm et al., 2005; Wessman et al., 2004). Mesic systems exhibit a greater increase in LAI than arid or semi-arid systems after woody encroachment and LAI in mesic shrub thickets often surpasses LAI for forest communities in the same region (Brantley \& Young, 2007; Knapp et al., 2008; Lett \& Knapp, 2003). Such large changes in LAI may substantially alter ecosystem $\mathrm{C}$ cycling but great uncertainty exists regarding effects of woody encroachment on global C sequestration (Brantley \& Young, 2010a; Briggs et al., 2005; Houghton, 2003; Jackson et al., 2002). Remote sensing of mesic shrub canopies may provide important evidence for effects of woody encroachment in regional and global C cycles (Grace et al., 2007; Turner et al., 2004), but the limitations of

Table 1

Summary of vegetation indices, algorithms and sources for vegetation indices used to estimate leaf area index in two shrub thickets.

\begin{tabular}{|c|c|c|}
\hline Index description & Algorithm & Source \\
\hline Normalized difference vegetation index(NDVI) & $\frac{\left(R_{800}-R_{670}\right)}{\left(R_{800}+R_{670}\right)}$ & Rouse et al., 1974 \\
\hline Modified chlorophyll absorption ratio index (MCARI) & {$\left[\left(R_{700}-R_{670}\right)-0.2\left(R_{700}-R_{550}\right)\right]\left(\frac{R_{700}}{R_{670}}\right)$} & Daughtry et al., 2000 \\
\hline Triangular vegetation index (TVI) & $0.5\left[120\left(R_{750}-R_{550}\right)-200\left(R_{670}-R_{550}\right)\right]$ & Broge \& Leblanc, 2000 \\
\hline Modified chlorophyll absorption ratio index 1 (MCARI1) & $1.2\left[2.5\left(R_{800}-R_{670}\right)-1.3\left(R_{800}-R_{550}\right)\right]$ & Haboudane et al., 2004 \\
\hline Modified chlorophyll absorption ratio index 2 (MCARI2) & $\frac{1.5\left[2.5\left(R_{800}-R_{670}\right)-1.3\left(R_{800}-R_{550}\right)\right]}{\sqrt{\left(2 R_{800}+1\right)^{2}-\left(6 R_{800}-5 \sqrt{R_{670}}\right)-0.5}}$ & Haboudane et al., 2004 \\
\hline Modified triangular vegetation index (MTVI2) & $\frac{1.5\left[1.2\left(R_{800}-R_{550}\right)-2.5\left(R_{670}-R_{550}\right)\right]}{\sqrt{\left(2 R_{800}+1\right)^{2}-\left(6 R_{800}-5 \sqrt{R_{670}}\right)-0.5}}$ & Haboudane et al., 2004 \\
\hline Chlorophyll index & $\frac{R_{750}}{\left(R_{700}+R_{710}\right)-1}$ & Gitelson et al., 2005 \\
\hline
\end{tabular}


standard vegetation indices are the same as those observed in tropical systems and new vegetation indices need to be evaluated.

Mesic shrub thickets provide an ideal model system to evaluate vegetation indices. They are often homogeneous in canopy structure and species composition and LAI values can range from $<1$ to $>12$, depending on site characteristics and species. The two shrub species studied here also show little variation in leaf chlorophyll concentration, an important biochemical parameter that affects reflectance. Lastly, there is increasing interest in the effects of shrub expansion of aboveground productivity of ecosystems. Our goal was to evaluate the potential for a variety of hyperspectral algorithms to accurately predict LAI for two mesic shrub communities. Our primary objective was to compare values from a variety of hyperspectral vegetation indices to direct measurements of LAI (from leaf litterfall) in dense shrub thickets. A second objective was to examine correlations between LAI estimates from indirect ground-sampling methods, which also saturate at high LAI values, and vegetation indices. Correlations between two indirect methods that saturate at similar levels could lead to overestimation of the potential of some remotesensing products to estimate LAI accurately. Other considerations in calibrating remote sensing indices with ground observations, including spatial resolution, variations in canopy architecture and variability of leaf chlorophyll concentration are also discussed.

\section{Methods}

\subsection{Study site}

Field work was conducted in two shrub thickets in Virginia, USA. General site information is provided in Table 2. Each site is dominated ( $>90 \%$ of woody cover) by individuals of a single, large ( $~ 5$ m canopy height) shrub species (Fig. 1). The first study site, Hog Island, is part of the Virginia Coast Reserve, an NSF-funded Long-Term Ecological Research site owned and managed by The Nature Conservancy. Dense thickets of Morella cerifera dominate in the mesic swales located between dune ridges and $M$. cerifera currently covers $\sim 40 \%$ of the upland area on the island (Young et al., 2007). Formerly known as Myrica cerifera (Wilbur, 1994) and commonly known as wax myrtle, $M$. cerifera is a native, evergreen, nitrogen-fixing shrub common along the southeastern Atlantic coast. LAI varies widely among sites from $~ 1$ in some older sites to $>12$ in the youngest thickets (Brantley \& Young, 2007). The second site is on Ft. A.P. Hill, Virginia and consists of two thickets located on either side of a road that are dominated by Elaeagnus umbellata. Commonly known as Autumn olive, E. umbellata is an invasive, deciduous, nitrogen-fixing shrub native to Japan, China and Korea, which was introduced into cultivation in the U.S. in 1830 (Nestleroad et al., 1987). It was often planted to stabilize soils and provide wildlife cover and is now commonly found along roadsides, in abandoned agricultural fields and in other disturbed areas throughout the central and eastern United States (Baer et al., 2006; BenítezMalvido \& Martínez-Ramos, 2002).

\subsection{Leaf area index and canopy chlorophyll content}

Forty plastic litter traps, $\sim 0.30 \mathrm{~m}^{2}$ in area and $0.15 \mathrm{~m}$ deep, were placed in M. cerifera shrub thickets in April 2004. Litter was collected periodically from April 2004 to May 2009 as part of a long-term project to quantify changes in C cycling on barrier islands after shrub expansion (Brantley \& Young, 2010a). In August 2008, 15 plastic litter traps were placed in two E. umbellata thickets and litter was collected after leaf fall in November 2008. Litter was dried at $70{ }^{\circ} \mathrm{C}$ for $4-5$ days, separated into leaf, woody and reproductive (i.e. fruits and flower parts) components, and weighed to the nearest $0.1 \mathrm{~g}$. Leaf litter mass was converted to LAI using values for specific leaf area (SLA). SLA was determined for each species using leaf tracings on a paper of known density (Brantley \& Young, 2010b). In 2004, peak LAI values (midAugust) in M. cerifera thickets were estimated with a Li-Cor LAI-2000 portable integrating radiometer (Li-Cor Biosciences, Lincoln, Nebraska, USA) above each litter trap and these data were reported in Brantley and Young (2007). In 2008, peak LAI was estimated for $E$. umbellata at each litter trap site with the Li-Cor LAI-2000. At each site where litter was collected, leaf samples from the upper canopy were collected from both species (2008 only) for analysis of chlorophyll content using methods recommended by Šesták (1971). Chlorophyll was extracted using a 100\% acetone solution and samples were ground, filtered, and analyzed using a Spectronic 21 spectrophotometer. Chlorophyll concentrations were calculated using equations given by Holm (1954). Results of field observations are summarized in Table 3.

\subsection{Airborne image acquisition}

The airborne hyperspectral mission for 2004 was flown using the Portable Hyperspectral Imager for Low-Light Spectroscopy (PHILLS) (Davis et al., 2002). Images were post-processed for radiometric calibration to provide data that is within $\pm 5 \%$ of absolute radiance. Calibrated radiance data were converted to surface reflectance values, using MODTRAN4 radiative transfer code to correct for atmospheric absorption and scattering components. Hyperspectral images for 2008 were provided by SpectIR using the ProSpecTIR VIS hyperspectral imaging spectrometer (SpectIR Corp., Reno, NV, USA). Aircraft, flight and sensor characteristics are described in Table 3. Images were collected under cloud-free conditions and data were post-processed to minimize geometric and radiometric (e.g., bi-directional) effects. For both flights ground reflectance radiometry was used to calibrate the data based on target endmembers collected in-scene with the ASD FieldSpec Pro Full Range reflectance radiometer (Analytical Spectral Devices, Inc., Boulder, CO, USA). This effectively placed the scene into reflectance units and helped minimize variations due solely to atmospheric effects. Calibration was performed using the empirical line calibration method within ENVI (RSI, Inc). Transformation of the PHILLS data was accomplished using the SpectIR data as a reference to normalize the bands. Extraction of pixels and subsequent calculation of indices at specific wavelengths from the 2004 PHILLS data were normalized to the reference 2008 SpectIR data using a histogram matching procedure following Jensen (2005):

$$
D N_{\text {new }}=\left(D N_{t}-M E A N_{t} / \operatorname{STD}_{t}\right) S T D_{r}+M E A N_{r}
$$

where $D N_{\text {new }}$ denotes the new spectral band(s) (PHILLS), $D N_{t}$ denotes the digital number values for the image to be transformed (PHILLS band), $M E A N_{t}$ denotes the statistical mean of the image to be transformed (PHILLS band), $S T D_{t}$ denotes the standard deviation of the image to be transformed (PHILLS band), STD $r$ denotes the standard deviation of the reference image (SpectIR band), and MEAN $N_{r}$ denotes the statistical mean of the image to be transformed (SpectIR band).

Table 2

Site descriptions for two shrub thickets in Virginia, USA.

\begin{tabular}{|c|c|c|c|c|c|}
\hline Location & Dominant species & Latitude & Longitude & Mean annual temperature $\left({ }^{\circ} \mathrm{C}\right)$ & Mean annual precipitation $(\mathrm{mm})$ \\
\hline Hog Island, Northhampton County, VA & Morella cerifera & $37.449 \mathrm{~N}$ & $75.667 \mathrm{~W}$ & $14.2^{\mathrm{a}}$ & $1065^{\mathrm{a}}$ \\
\hline Fort A.P. Hill, Caroline County, VA & Elaeagnus umbellata & $38.093 \mathrm{~N}$ & $77.335 \mathrm{~W}$ & $13.6^{\mathrm{a}}$ & $1167^{\mathrm{a}}$ \\
\hline
\end{tabular}

a Source: National Climatic Data Center (2004), Asheville, NC. 


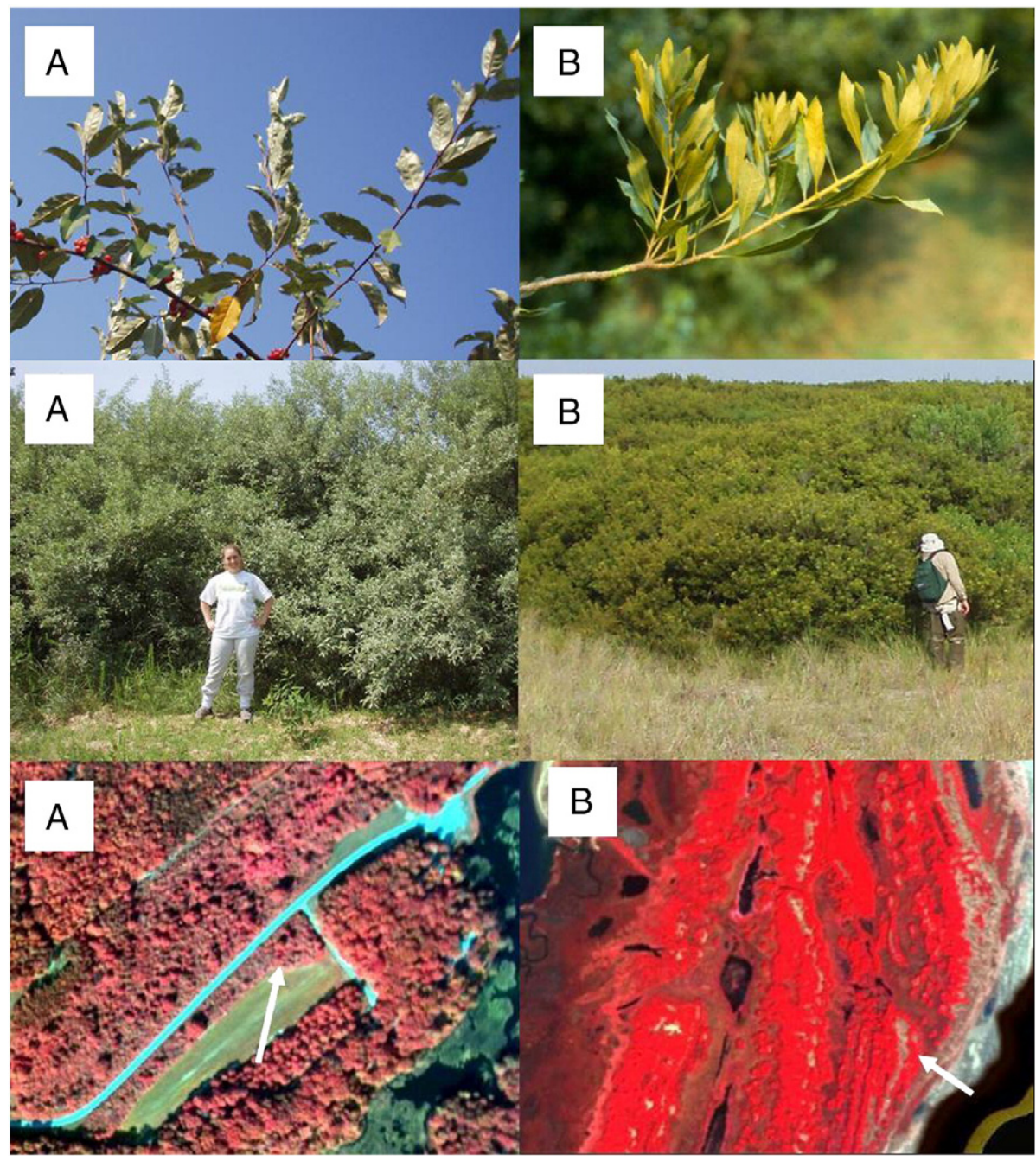

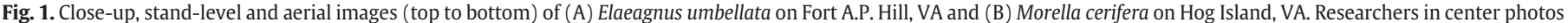
are shown for scale (locations of photos are denoted by arrows in aerial images).

Given the close acquisition times, spectral, spatial, radiometric and ground features for each airborne mission, this effectively normalized each image set for comparative stress calculations based upon reflectance signatures.

\subsection{Analysis}

Representative spectra from a midpoint on Hog Island for the two flights are shown and the wavelengths used in representative indices are shown to illustrate fundamental differences in chemical and/or structural mechanisms that affect reflectance values for those indices (Fig. 2). Pixels for analysis were selected from each image based on GPS locations of each litter trap taken with a Trimble GeoXT handheld GPS (Trimble, Sunnyvale, CA, USA) and corresponding spectra were extracted. Pixel values for vegetation indices from hyperspectral imagery were compared to LAI measurements from litterfall and estimates from the LAI-2000 using Pearson correlation analysis. Comparisons of hyperspectral indices and ground-sampled LAI estimated were completed for data from M. cerifera thickets in 2004 and 2008 and for E. umbellata from 2008. Potential of select indices to accurately predict LAI was also evaluated using simple linear regression analysis between values from images and ground sampling data. Results from litterfall and the LAI-2000 were also compared with Pearson correlation analysis using data from M. cerifera in 2004 and $E$. umbellata in 2008.

\section{Results and discussion}

Correlations between NDVI and other indices, such as SAVI and MCARI and derivations thereof, that have been previously used to estimate LAI based on canopy reflectance ranged from very poor to acceptable depending on a number of factors including species, image spatial resolution and ground-sampling method used for comparison (Tables 4 and 5). NDVI was a relatively poor predictor of LAI in $M$. cerifera canopies across years and methods of ground sampling (Fig. 3). NDVI was a more effective indicator of LAI in E. umbellata, especially when $1 \mathrm{~m}^{2}$ pixels were aggregated (Fig. 3). Differences between the two species in effectiveness of NDVI for predicting LAI may be due to differences in the range of LAI values observed for each species or by differences in canopy structure. Saturation of NDVI was more likely in $M$. cerifera, where individual litterfall LAI values often exceeded 10, than in E. umbellata where maximum litterfall LAI was $\sim 4$. Relevant differences in canopy structure that may also affect the potential of NDVI to accurately predict LAI in these species are discussed in the later part.

Algorithms developed to improve LAI predictions in crop canopies (MCARI, MCARI1, MCARI2, TVI, and MTVI2) performed poorly in the two natural systems examined here (Tables 4 and 5). There were no significant relationships between these indices and ground-sampled LAI for E. umbellata (Table 5). There were significant relationships for $M$. cerifera, however correlation was generally poor and effectiveness of these indices was inconsistent across years and methods. 
Table 3

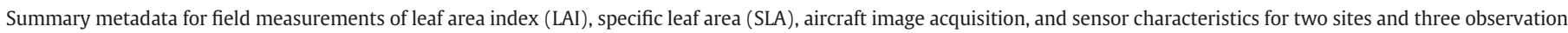
periods. All chlorophyll values and LAI-2000 values were taken in July/August of the same year.

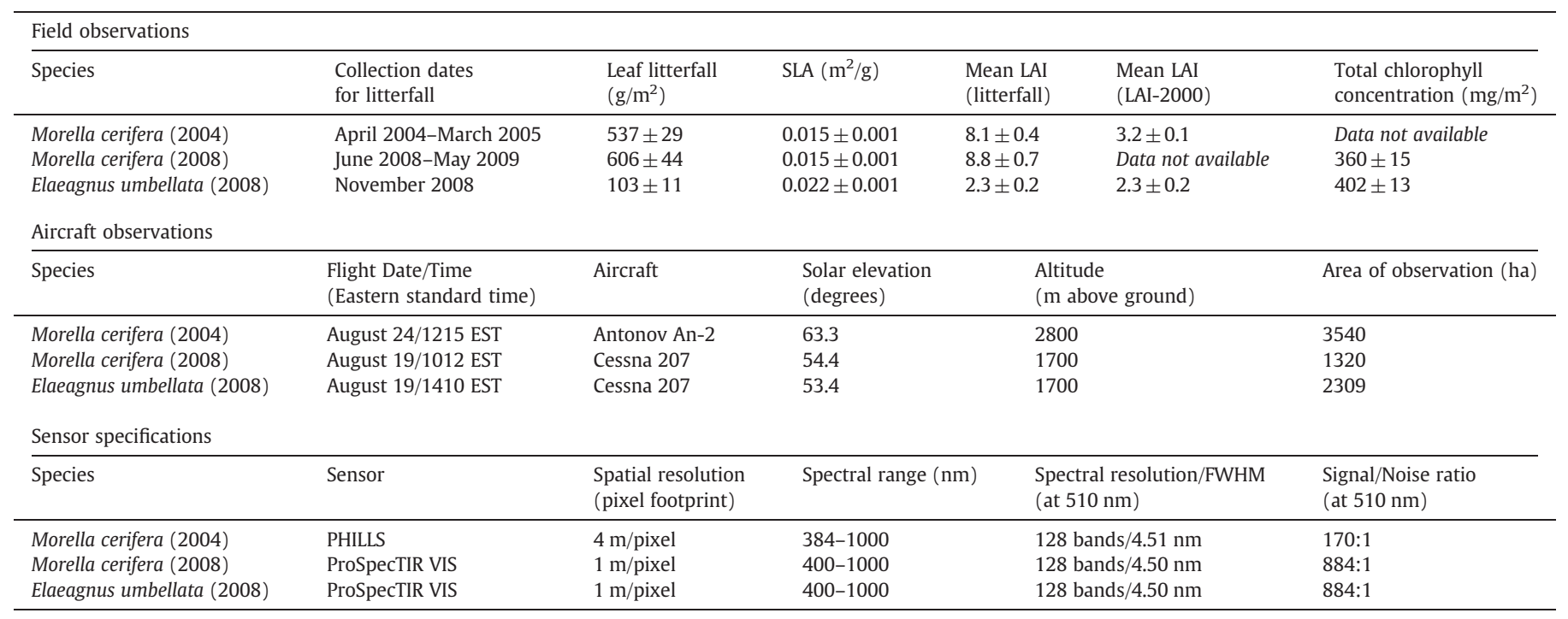

Regression analysis also showed that the potential sensitivity of these indices (and of NDVI, Fig. 3) to detect small variations in LAI using predictive modeling was low due to the small slopes of the regression models relative to potential error (data not shown). Relationships between some of these indices (specifically MCARI1 and TVI) and M. cerifera LAI estimates from the LAI-2000 were strongest among this group (Table 4) but this result might be expected as these indices were largely derived and tested using modeled reflectance derived from estimates of LAI based on similar indirect measurements (Haboudane et al., 2004).

Red-edge and derivative reflectance indices were significantly and highly related to variations in LAI and these were the best indices to predict LAI across species, years ( $M$. cerifera only) and methods of ground sampling (Tables 4 and 5). In addition to the high sensitivity of these indices to variations in high LAI canopies, many of these indices also displayed higher variations across the range of LAI values which would improve the eventual application of such indices for predictive modeling (Fig. 4). For M. cerifera, no single algorithm was consistently best across years and methods but several indices $\left(C I, D_{705} / D_{722}\right.$ and $\left.\mathrm{D}_{730} / \mathrm{D}_{706}\right)$ consistently had correlation coefficients $>0.70$ when using either 2004 imagery or pixel aggregates from 2008 (Table 4). For $E$.

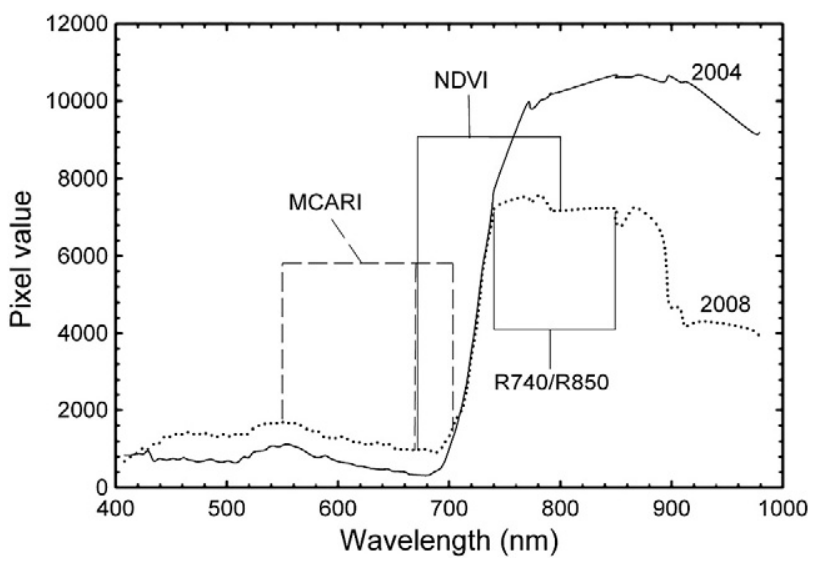

Fig. 2. Representative spectra from a midpoint on Hog Island from flights in 2004 and 2008. Wavelengths of select indices are illustrated to show differences in spectral regions among various groups of indices. umbellata, $\mathrm{R}_{750} / \mathrm{R}_{710}$ was consistently the index best related to LAI for all comparisons (pixel size and/or method of collection; Table 5). When considering both species across 2008 only, CI and the two derivative indices, $D_{705} / D_{722}$ and $D_{730} / D_{706}$, were uniformly the most reliable predictors of LAI (Tables 4 and 5; Fig. 4). Thus, our results suggest that indices using wavelengths in the red edge region, and that were originally developed for chlorophyll estimation, were the most capable of accurately differentiating high LAI values in these shrub thickets. Although these indices have previously been related to stress detection, there is no relationship between stress and chlorophyll concentration in these systems (Naumann et al., 2007, 2008b, 2009; see discussion below). The close correlation between red-edge indices and LAI may either be related to increased scattering by mesophyll as a function of increased mesophyll content of the canopy or it may simply be an indicator of total canopy chlorophyll. Given the lack of variation in leaf chlorophyll concentration across each site, total canopy chlorophyll would simply be a function of LAI.

In high LAI canopy systems, reflectance signatures tend to be dominated by leaf biochemical properties, canopy chlorophyll content and other confounding canopy characteristics (Asner et al., 2000; Asner et al., 2004). For the M. cerifera shrub thickets that we studied, steep environmental gradients exist causing variations in salinity stress (Naumann et al., 2008a, 2009), and laboratory studies have demonstrated that salinity can lead to changes in reflectance characteristics (Naumann et al., 2007, 2008b). However, unlike most woody species, $M$. cerifera retains chlorophyll even under conditions of stress, and chlorophyll does not change regardless of location relative to salinity (Naumann et al., 2007, 2008b, 2009). There were no significant differences in total chlorophyll content, chlorophyll $a$ or chlorophyll $b$ concentrations for $M$. cerifera (all $P>0.05 ; 360 \pm$ $14 \mathrm{mg} \mathrm{m}^{-2}, 211 \pm 8 \mathrm{mg} \mathrm{m}^{-2}, 148 \pm 8 \mathrm{mg} \mathrm{m}^{-2}$, respectively) and there was very little variability in $E$. umbellata $\left(409 \pm 12 \mathrm{mg} \mathrm{m}^{-2}\right.$, $239 \pm 9 \mathrm{mg} \mathrm{m}^{-2}, 177 \pm 6 \mathrm{mg} \mathrm{m}^{-2}$, respectively). Because chlorophyll content was consistent across the range of observed LAI values for both species (Fig. 5), changes in relationships between LAI and reflectance stress indices in these systems are likely dominated by variations in LAI rather than differences in chlorophyll concentration due to stress. For example, there were significant relationships between $\mathrm{CI}$ and LAI across species and years (Tables 4 and 5). The lack of variation in leaf-level chlorophyll content for either species indicates that those relationships are due to changes in LAI that affect 
Table 4

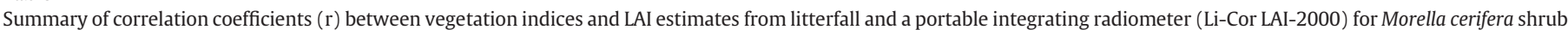

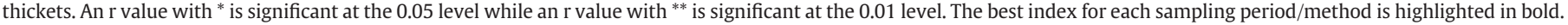

\begin{tabular}{|c|c|c|c|c|}
\hline Index & $\begin{array}{l}\text { Morella cerifera } \\
(2004) / \text { LAI-2000 }\end{array}$ & $\begin{array}{l}\text { Morella cerifera } \\
\text { (2004) Litterfall }\end{array}$ & $\begin{array}{l}\text { Morella cerifera } \\
\text { (2008) Litterfall }\end{array}$ & $\begin{array}{l}\text { Morella Cerifera (2008) } \\
\text { Aggregate/Litterfall }\end{array}$ \\
\hline NDVI & $0.518^{* *}$ & $0.430^{* *}$ & $0.524^{*}$ & $0.492^{* *}$ \\
\hline MCARI & 0.095 & 0.303 & 0.338 & $0.455^{* *}$ \\
\hline MCARI1 & $0.691^{* *}$ & $0.586^{* *}$ & 0.397 & $0.515^{* *}$ \\
\hline MCARI2 & $0.409^{* *}$ & $0.445^{* *}$ & $0.524^{* *}$ & 0.295 \\
\hline TVI & $0.641^{* *}$ & $0.541^{* *}$ & $0.346^{*}$ & $0.439^{* *}$ \\
\hline MTVI2 & 0.063 & 0.134 & 0.397 & 0.295 \\
\hline $\mathrm{CI}$ & $0.810^{* *}$ & $0.884^{* *}$ & $0.572^{* *}$ & $0.773^{* *}$ \\
\hline $\mathrm{R}_{740} / \mathrm{R}_{850}$ & $0.651^{* *}$ & $0.592^{* *}$ & $0.655^{* *}$ & $0.773^{* *}$ \\
\hline $\mathrm{R}_{761 /} \mathrm{R}_{757}$ & $0.784^{* *}$ & $0.902^{* *}$ & 0.000 & 0.187 \\
\hline $\mathrm{R}_{750} / \mathrm{R}_{710}$ & $0.678^{* *}$ & $0.718^{* *}$ & $0.711^{* *}$ & $0.705^{* *}$ \\
\hline $\mathrm{D}_{705} / \mathrm{D}_{722}$ & $0.814^{* *}$ & $0.881^{* *}$ & $0.497^{*}$ & $0.705^{* *}$ \\
\hline $\mathrm{D}_{730} / \mathrm{D}_{706}$ & $0.743^{* *}$ & $0.819^{* *}$ & 0.297 & $0.760^{* *}$ \\
\hline$D_{\max } / D_{720}$ & $0.814^{* *}$ & $0.917^{* *}$ & $0.562^{*}$ & 0.100 \\
\hline $\mathrm{D}_{\max } / \mathrm{D}_{745}$ & $0.574^{* *}$ & $0.541^{* *}$ & $0.475^{*}$ & $0.729^{* *}$ \\
\hline $\mathrm{D}_{715} / \mathrm{D}_{705}$ & $0.644^{* *}$ & $0.785^{* *}$ & $0.369^{*}$ & $0.521^{* *}$ \\
\hline
\end{tabular}

total canopy chlorophyll content rather than variation in chlorophyll throughout the thicket.

The apparent potential of various algorithms evaluated herein to accurately estimate LAI also depended heavily on the method of ground sampling used for comparison. When available, direct measurements of LAI such as litterfall or destructive sampling should be used for calibrating vegetation indices because of the inherent constraints on indirect methods (Brantley \& Young, 2007; Gower et al., 1999). Contrasting the results of indices for litterfall LAI and LAI2000 values illustrates the risk of relying solely on indirect groundsampling for calibration of indices. Relationships between litterfall LAI and LAI-2000 estimates were significant and positive for both species and absolute values for LAI were highly comparable for the two methods in E. umbellata thickets but absolute values of LAI for $M$. cerifera thickets diverged significantly between the two methods (Fig. 6). Litterfall LAI and LAI-2000 values were similar at the lowest LAI values but differences increased linearly as LAI increased in $M$. cerifera (Fig. 6). Optical saturation with the LAI-2000 often occurs $\sim 4$ (Gower et al., 1999), and this may explain differences in the results from these two species. There was not enough overlap in LAI values between the two species to thoroughly test the potential effects of canopy structure on saturation thresholds but it is possible that saturation points may be lower or higher depending on species. A saturation point of four is near the same threshold often cited for saturation of NDVI and other vegetation indices, although reasons for saturation are different (Asner et al., 2000; Haboudane et al., 2004;
Wang et al., 2005). Agreement between NDVI and portable integrating radiometer measurements for E. umbellata was strong and the LAI2000 provided acceptable accuracy and sensitivity for groundsampling this species. However, because many vegetation indices and the portable integrating radiometer saturate at similar levels, strong statistical relationships between these methods for other systems, such as $M$. cerifera shrub thickets or tropical systems with high LAI values, are not necessarily indicative of the potential accuracy of a given algorithm. In such cases, the underestimation of LAI from the LAI-2000 could lead to overestimation of the effectiveness of vegetation indices that saturate near the same threshold. Resulting underestimation of LAI could lead to underestimates of related ecological phenomena such as ANPP.

Several variables other than algorithm selection also affected relationships between ground sampling and vegetation indices and we will address the most important of those variables here. When considering the entire set of indices, best results were obtained for images with larger pixel sizes or for aggregated pixels for both species. Higher spatial resolution generally improves accuracy of LAI estimates from airborne or space-borne platforms, especially as sensors reach saturation (Asner et al., 2000), but our analyses indicates that agreement between vegetation indices and ground sampling does not necessarily improve as spatial resolution improves. Correlations between ground samples and vegetation indices calculated from the $1 \mathrm{~m}^{2}$ pixels were relatively poor (Tables 4 and 5). When values for four adjacent pixels were averaged, relationships with ground-

Table 5

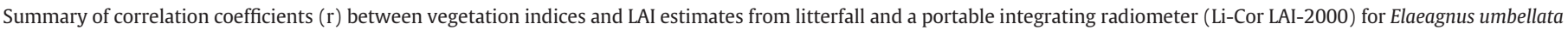

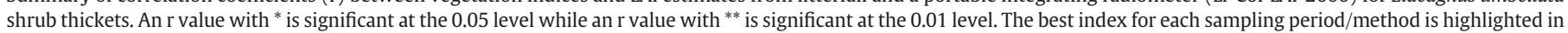
bold.

\begin{tabular}{|c|c|c|c|c|}
\hline Index & $\begin{array}{l}\text { Elaeagnus umbellata } \\
\text { (2008)/LAI-2000 }\end{array}$ & $\begin{array}{l}\text { Elaeagnus umbellata } \\
\text { (2008) Litterfall }\end{array}$ & $\begin{array}{l}\text { Elaeagnus umbellata } \\
\text { (2008) Aggregate/Litterfall }\end{array}$ & $\begin{array}{l}\text { Elaeagnus umbellata } \\
\text { (2008) Aggregate/LAI-2000 }\end{array}$ \\
\hline NDVI & 0.481 & 0.607 & $0.666^{*}$ & $0.757^{* *}$ \\
\hline MCARI & 0.355 & 0.095 & 0.502 & 0.566 \\
\hline MCARI1 & 0.032 & 0.302 & 0.158 & 0.089 \\
\hline MCARI2 & 0.539 & 0.445 & 0.442 & 0.510 \\
\hline TVI & 0.063 & 0.217 & 0.071 & 0.000 \\
\hline MTVI2 & 0.539 & 0.445 & 0.442 & 0.510 \\
\hline $\mathrm{CI}$ & 0.596 & 0.513 & $0.824^{* *}$ & $0.834^{* *}$ \\
\hline $\mathrm{R}_{740} / \mathrm{R}_{850}$ & $0.601^{*}$ & $0.725^{* *}$ & $0.760^{* *}$ & $0.767^{* *}$ \\
\hline $\mathrm{R}_{761 /} \mathrm{R}_{757}$ & 0.230 & $0.687^{*}$ & $0.632^{*}$ & 0.249 \\
\hline $\mathrm{R}_{750} / \mathrm{R}_{710}$ & $0.666^{*}$ & $0.742^{* *}$ & $0.825^{* *}$ & $0.843^{* *}$ \\
\hline $\mathrm{D}_{705} / \mathrm{D}_{722}$ & 0.344 & $0.641^{*}$ & $0.796^{* *}$ & $0.767^{* *}$ \\
\hline $\mathrm{D}_{730} / \mathrm{D}_{706}$ & 0.486 & 0.526 & $0.827^{* *}$ & $0.737^{* *}$ \\
\hline$D_{\max } / D_{720}$ & 0.118 & 0.373 & $0.601^{*}$ & 0.559 \\
\hline $\mathrm{D}_{\max } / \mathrm{D}_{745}$ & 0.322 & 0.089 & 0.396 & $0.666^{*}$ \\
\hline $\mathrm{D}_{715} / \mathrm{D}_{705}$ & 0.354 & 0.130 & 0.455 & $0.692^{*}$ \\
\hline
\end{tabular}



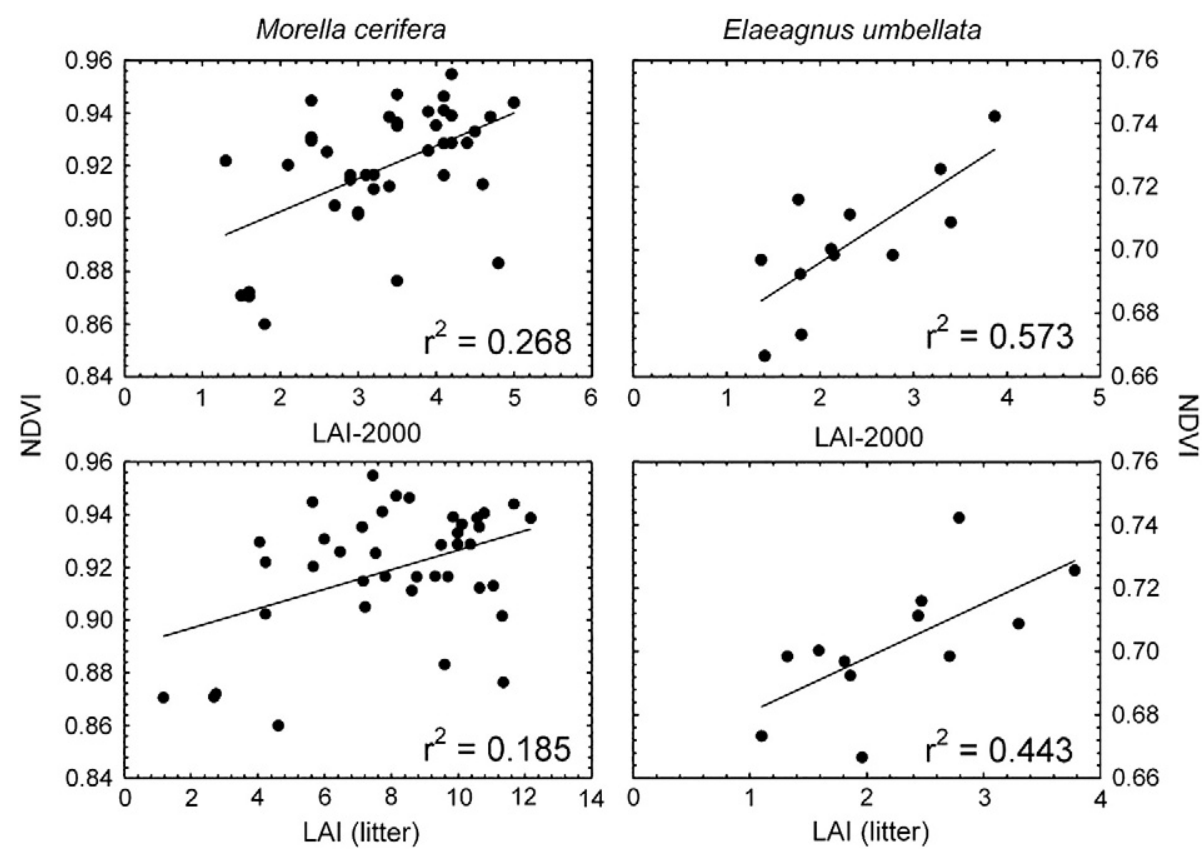

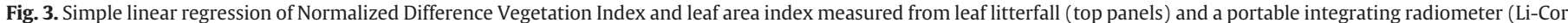
LAI-2000) (bottom panels) for two shrub species.

sampled values improved substantially. Larger pixels and/or pixel aggregates may simply improve spatial agreement between pixel values and indirect methods such as the LAI-2000 or hemispheric photography because the area sampled is more similar (Fig. 7). The area represented by the portable integrating radiometer (which varies with canopy height) will generally include many square meters of canopy space and may be better related spatially to larger pixels if the absolute values are accurate (Fig. 7) (Li-Cor LAI-2000 manual).
The potential importance of matching ground-sampling area with image sampling can be further demonstrated in our results. While litterfall methods are considered highly accurate, individual litter traps represent a very small area of the canopy $(0.30 \mathrm{~m} 2$ in this study) compared to other methods. The strongest relationship for $M$. cerifera with NDVI was observed between small pixels and litter traps $\left(1 \mathrm{~m}^{2}\right.$ and $0.30 \mathrm{~m}^{2}$ respectively). At this small scale, however, high levels of accuracy (sub-meter) for locating ground sampling points is
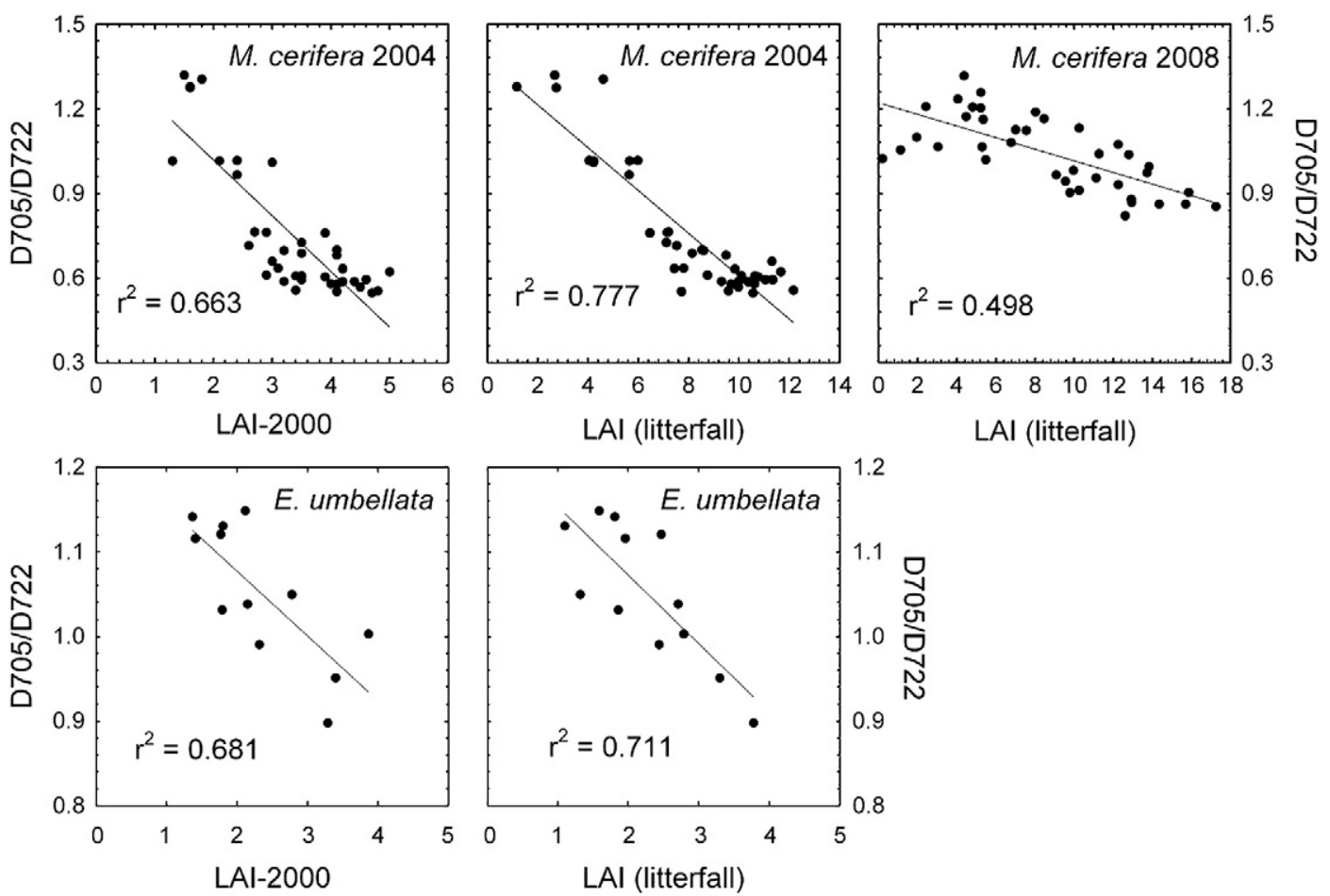

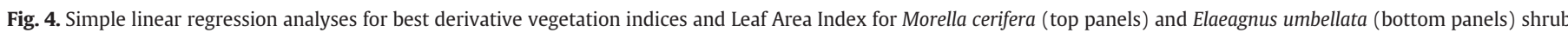
thickets. 


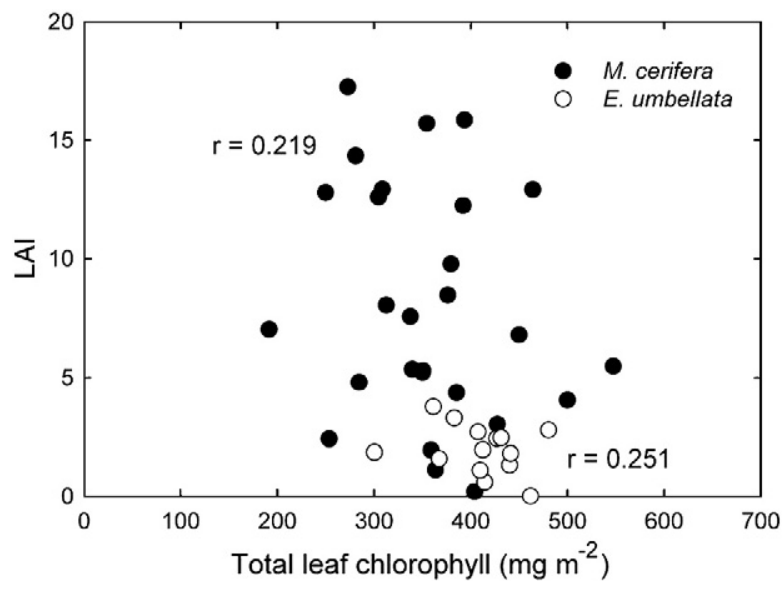

Fig. 5. Simple linear regression analyses for chlorophyll content and Leaf Area Index for Morella cerifera (dark circles) and Elaeagnus umbellata(empty circles).

important to ensure that the values are representative of the same physical location. Relationships between $M$. cerifera litterfall LAI and other indices may be improved over NDVI because other indices are less likely to saturate and this affect is stronger than the effect of spatial sample size or because $M$. cerifera canopies are more uniformly dense (personal observation) and a litterfall LAI values is able to represent the entire pixel. The strongest relationship between $E$. umbellata and NDVI were for $4 \mathrm{~m}^{2}$ pixel aggregates and the LAI-2000. Each method demonstrated here has a different sampling area based on ground-sampling methodology or pixel size and differences in the physical area sampled by various methods may lead to poor relationships because of the inherent heterogeneity characteristic of most canopies. If high resolution imagery is used (e.g. $1 \mathrm{~m}^{2}$ pixel size), aggregations of pixels may provide better relationships with ground measurements that represent larger areas because a single pixel may not adequately represent variations in the area sampled on the ground. Similarly, relatively large pixels on images with lower spatial resolution (e.g. $30 \mathrm{~m}$ ) may not be adequately represented by a single litter trap.
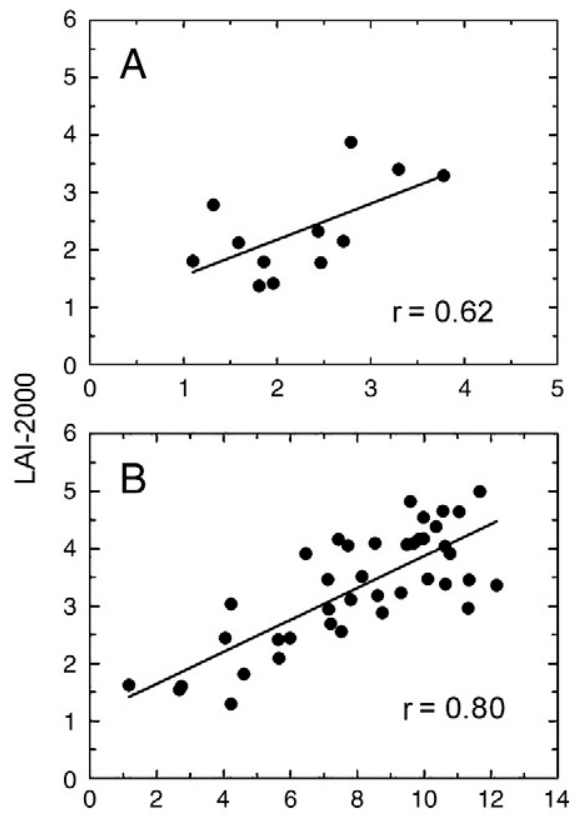

LAl (litterfall)

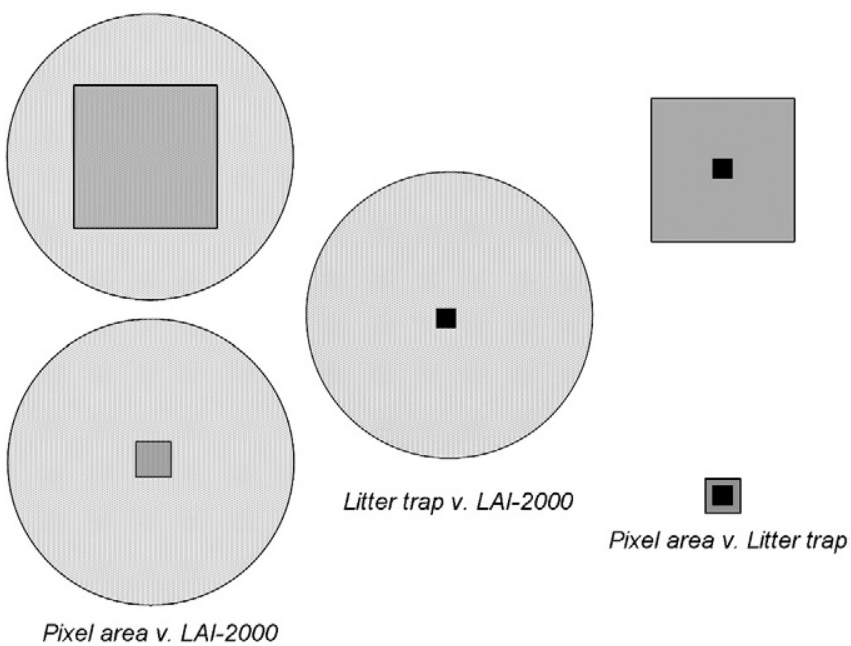

Fig. 7. Relative footprints of various sampling methods used to estimate leaf area index. Relative pixel sizes from two hyperspectral images are represented by gray boxes $\left(1 \mathrm{~m}^{2}\right.$ on bottom and $16 \mathrm{~m}^{2}$ on top). Litter traps are represented by black boxes $\left(0.30 \mathrm{~m}^{2}\right)$. LAI-2000 results are represented by circles and the sampling area is estimated based on canopy height. Representations are to scale except for LAI-2000 which is an approximation.

Reflectance values using smaller pixels also generally showed a greater degree of variability, likely because of the inherent structural heterogeneity of natural canopies caused by the presence of small gaps, clumps of foliage, large stems, etc. Other effects of a heterogeneous canopy include the casting of shadows that affect canopy reflectance, change pixel values and (Middleton et al., 2009). Larger pixels, or aggregates of smaller pixels, reduce this variation by averaging index values for several pixels. Alternatively, Middleton et al. (2009) demonstrated a correction technique to account for the differential effects of shadows on reflectance values that may prove preferable in many circumstances where maintaining finer spatial resolution is desirable. Unlike techniques that specifically address shadows, better correlations in indices with larger pixels may simply be an artifact of reducing this variation across a wider area. Aggregating smaller pixels
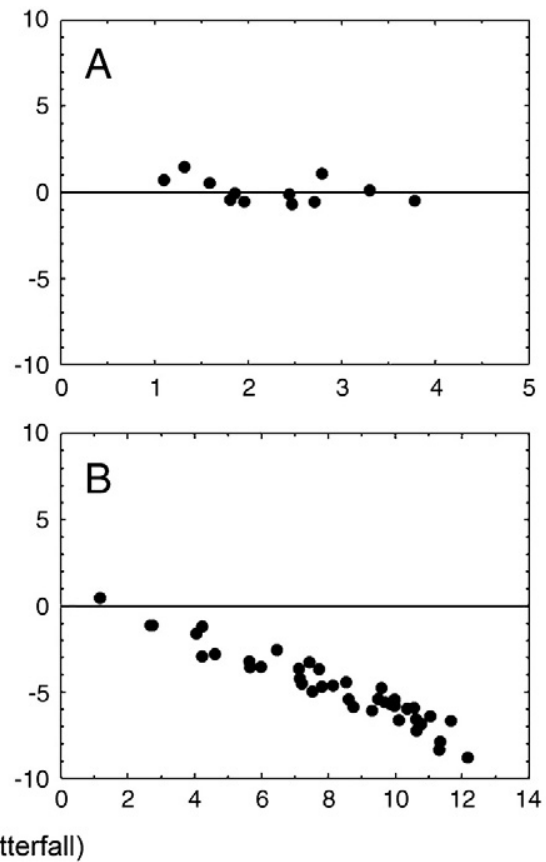

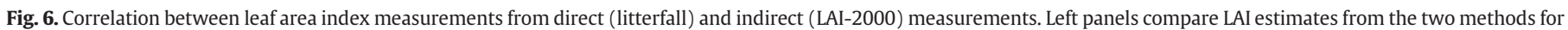
Elaeagnus umbellata (A) and Morella cerifera (B). Right panels show the divergence of LAI-2000 estimates from litterfall LAI. 
may also mitigate any inaccuracies in ground-sample plots where highly-precise locations (e.g. sub-meter) ground-sampling are not available. Whether aggregating pixels is applicable to these studies may depend on the scale of interest and size of canopy footprint produced from the preferred ground sampling technique.

Finally, it is difficult to decouple the effects of saturation and canopy architecture because there was little overlap between LAI values between the two species. However, the high LAI in M. cerifera shrub thickets requires some discussion and differences in canopy architecture may also help explain why LAI is more difficult to estimate in some canopies. Variations in leaf orientation (i.e., leaf angle and leaf azimuth) and branching patterns affect distribution of leaves within a canopy and strongly influences reflectance at the stand level (Kempf \& Pickett, 1981; Nicola \& Pickett, 1983; Sands, 1995; Falster \& Westoby, 2003). Canopy structure at the leaf and stand level varies substantially between the two species studied here. Elaeagnus umbellata has lower leaf angles than M. cerifera (i.e. leaves are horizontally rather than vertically inclined) and E. umbellata foliage is biased towards the south where as M. cerifera foliage is randomly oriented with no directional bias (Brantley \& Young, 2010b). Additionally, leaves of E. umbellata are more evenly distributed within the canopy which reduces leaf clumping and increases efficiency of light interception in relation to biomass (Brantley \& Young, 2010b). Highly clumped foliage and high leaf angles are likely the reason $M$. cerifera thickets can maintain relatively high LAI values, and these characteristics combine to make both optical methods of LAI estimation and remote-sensing methods difficult. A solution to improve accuracy for indirect optical methods, such as hemispheric photography and radiometric methods, is to apply a correction coefficient to improve ground-sampling accuracy (DeBlonde et al., 1994). Improved ground-sampling accuracy, combined with recognition of the effects of canopy structure on reflectance and the application of the derivative indices discussed previously has potential to greatly improve accuracy of LAI estimates in certain canopies.

\section{Summary and conclusions}

Our analysis points to a number of recommendations for improving the accuracy of LAI estimates in high LAI canopies from remote-sensing platforms. To address the issue of saturation, increased consideration should be given to use of indices using wavelengths in the red-edge region. These indices reflect variations in total canopy chlorophyll content, and may be especially useful in communities where LAI exceeds 4 and leaf chlorophyll concentrations are unrelated to variations in LAI. Second, comparisons between LAI and remotely derived vegetation indices have often used groundsampling measurements based on indirect measurements that are limited in sensitivity due to optical saturation. In dense canopies, correlation between an underestimated LAI value and a vegetation index that saturates at a similar value may lead to erroneous conclusions regarding the potential of such an algorithm to accurately predict LAI. Ground-sampling should include at least a sub-sample of direct measurements such as litterfall or destructive sampling to confirm results from broader indirect sampling or allow determination of an empirical relationship that can be used to correct for saturation in indirect estimates when they are not in agreement with direct LAI measurements. If ground sampling is not possible, some effort should be made to perform direct sampling on areas with similar species assemblages and/or community structure to provide evidence of accuracy for indirect measurements. Lastly, consideration needs to be given regarding the relationship between pixel size/ spatial resolution and size of ground sampling units. When high resolution imagery is used (e.g. $1 \mathrm{~m}^{2}$ pixel), aggregations of pixels may provide better relationships with ground measurements that were made over larger areas and account for heterogeneity in canopies by averaging across multiple pixels.

We present a comprehensive comparison of vegetation indices using algorithms from various regions of the visible and infrared spectrum as derived from hyperspectral imagery and their relationship to directly measured LAI values from a simple, established method of measuring LAI. Our results show that, at least for the two communities studied, many algorithms developed to improve LAI estimates over NDVI remain insensitive to variations in canopies with $\mathrm{LAI}>4$. Vegetation indices in other regions, especially those related to the red edge spectral region may have greater potential for detecting variations in high LAI canopies. While the limitations of indirect measurement of LAI have been addressed several times previously (Brantley \& Young, 2007; Deblonde et al., 1994; Gower et al., 1999), these techniques and/or instruments continue to be used for groundsampling and incorporated into reflectance models that depend on accurate measurement of LAI. Underestimates of LAI could lead to similar underestimates of associated ecological phenomena, including primary productivity, hydrologic effects and nutrient cycling. With continued interest in monitoring regional and global C cycling using remote-sensing, reliable techniques of using hyperspectral imagery to accurately estimate LAI are essential.

\section{Acknowledgements}

This research was supported, in part, by a grant to Donald R. Young from the United States Army Research Office. Additional support was provided by NSF grant DEB-008031 to the University of Virginia for LTER-related work at the Virginia Coast Reserve. Spencer Bissett and Kati Rubis provided assistance with field work and laboratory analysis. The Virginia Coast Reserve LTER staff assisted with island logistics.

\section{References}

Archer, S. (1989). Have southern Texas savannas been converted to woodlands in recent history? American Naturalist, 134, 545-561.

Asner, G. P., Nepstad, D., Cardinot, G., \& Ray, D. (2004). Drought stress and carbon uptake in an Amazon forest measured with spaceborne imaging spectroscopy. Proceedings of the National Academy of Science, 101, 6039-6044.

Asner, G. P., Townsend, A. R., \& Braswell, B. H. (2000). Satellite observation of El Niño effects on Amazon forest phenology and productivity. Geophysical Research Letters, 27, 981-984.

Baer, S. G., Church, J. M., Williard, K. W. J., \& Groninger, J. W. (2006). Changes in intrasystem $\mathrm{N}$ cycling form $\mathrm{N}_{2}$-fixing shrub encroachment in grassland: Multiple positive feedbacks. Agriculture, Ecosystems \& Environment, 115, 174-182.

Benítez-Malvido, J., \& Martínez-Ramos, M. (2002). Impact of forest fragmentation on understorey plant species richness in Amazonia. Conservation Biology, 17, $389-400$.

Bonan, G. B. (1993). Importance of leaf area index and forest type when estimating photosynthesis in boreal forests. Remote Sensing of Environment, 43, 303-314.

Brantley, S. T., \& Young, D. R. (2007). Leaf-area index and light attenuation in rapidly expanding shrub thickets. Ecology, 88, 524-530.

Brantley, S. T., \& Young, D. R. (2008). Shifts in litterfall and dominant nitrogen sources after expansion of shrub thickets. Oecologia, 155, 337-345.

Brantley, S. T., \& Young, D. R. (2010a). Shrub expansion stimulates soil C and N storage along a coastal soil chronosequence. Global Change Biology, 16, 2052-2061.

Brantley, S. T., \& Young, D. R. (2010b). Linking light attenuation, sunflecks, and canopy architecture in mesic shrub thickets. Plant Ecology, 206, 225-236.

Briggs, J. M., Knapp, A. K., Blair, J. M., Heisler, J. L., Hoch, G. A., Lett, M. S., et al. (2005). An ecosystem in transition: causes and consequences of the conversion of mesic grassland to shrubland. Bioscience, 55, 243-254.

Broge, N. H., \& Leblanc, E. (2000). Comparing prediction power and stability of broadband and hyperspectral vegetation indices for estimation of green leaf area index and canopy chlorophyll density. Remote Sensing of Environment, 76 , $156-172$.

Campbell, P. K. E., Middleton, E. M., McMurtney, J. E., Corp, L. A., \& Chappelle, E. W. (2007). Assessment of vegetation stress using reflectance or fluorescence measurements. Journal of Environmental Quality, 36, 832-845.

Curran, P. J., Dungan, J. L., \& Gholz, H. L. (1990). Exploring the relationship between reflectance red edge and chlorophyll content in slash pine. Tree Physiology, 7, $33-48$

Daughtry, C. S. T., Walthall, C. L., Kim, M. S., Brown de Colstoun, E., \& McMurtrey, J. E., III (2000). Estimating corn leaf chlorophyll concentration from leaf and canopy reflectance. Remote Sensing of Environment, 74, 229-239. 
Davis, C., Bowles, J., Leathers, R., Korwan, D., Downes, T. V., Snyder, W., et al. (2002). Ocean PHILLS hyperspectral imager: Design, characterization, and calibration. Optics Express, 10, 210-221.

Deblonde, G., Penner, M., \& Royer, A. (1994). Measuring leaf area index with the LAI2000 in pine stands. Ecology, 75, 1507-1511.

Falster, D. S., \& Westoby, M. (2003). Leaf size and angle vary widely across species: What consequences for light interception? The New Phytologist, 158, $509-525$.

Gitelson, A. A., Viña, A., Ciganda, C., Rundquist, D. C., \& Arkebauer, T. J. (2005). Remote estimation of canopy chlorophyll content in crops. Geophysical Research Letters, 32, L08403.

Gower, S. T., Kucharik, C. J., \& Norman, J. M. (1999). Direct and indirect estimation of leaf area index, $\mathrm{f}_{\mathrm{par}}$, and net primary production of terrestrial ecosystems. Remote Sensing of Environment, 70, 29-51.

Grace, J., Nichol, M., Disney, M., Lewis, P., Quaife, T., \& Bowyer, P. (2007). Can we measure terrestrial photosynthesis from space directly, using spectral reflectance and fluorescence? Global Change Biology, 13, 1484-1497.

Haboudane, D., Miller, J. R., Pattey, E., Zarco-Tejada, P. J., \& Stachan, I. B. (2004) Hyperspectral vegetation indices and novel algorithms for predicting green LAI of crop canopies: Modeling and validation in the context of precision agriculture. Remote Sensing of Environment, 90, 337-352.

Holm, G. (1954). Chlorophyll mutation in barley. Acta Agriculturae Scandinavica, 4 , $457-471$.

Horler, D. N. H., Dockray, M., \& Barber, J. (1983). The red edge of plant leaf reflectance. International Journal of Remote Sensing, 4, 273-288.

Houghton, R. A. (2003). Why are estimates of the terrestrial carbon balance so different? Global Change Biology, 9, 500-509.

Jackson, R. B., Banner, J. L., Jobbagy, E. G., Pockman, W. T., \& Wall, D. H. (2002) Ecosystem carbon loss with woody plant invasion of grasslands. Nature, 418 $623-626$.

Jensen, J. R. (2005). Introductory digital image processing: A remote sensing perspective (3rd ed.). Upper Saddle River, New Jersey, USA: Prentice Hall.

Kempf, J. S., \& Pickett, S. T. A. (1981). The role of branch length and angle in branching pattern of forest shrubs along a successional gradient. The New Phytologist, 88, $111-116$.

Knapp, A. K., Briggs, J. M., Collins, S. L., Archer, S. R., Bret-Harte, M. S., Ewers, B. E., et al. (2008). Shrub encroachment in North American grasslands: Shifts in growth form dominance rapidly alters control of ecosystem carbon inputs. Global Change Biology, $14,615-623$.

Lett, M. S., \& Knapp, A. K. (2003). Consequences of shrub expansion in mesic grassland: resource alterations and graminoid responses. Journal Vegetation Science, 14, 487-496.

Middleton, E. M., Cheng Y. Hilker, T., Black, T. A., Krishnan, P., Coops, N. C., et al. (2009) Linking foliage spectral response to canopy-level ecosystem photosynthetic lightuse efficiency at a Douglas-fir forest in Canada. Canadian Journal of Remote Sensing $35,166-188$.

National Climatic Data Center, Asheville, NC. 2004. Monthly station climate summaries (1971-2000) for Virginia. http://cdo.ncdc.noaa.gov/climatenormals/clim20/statepdf/va.pdf

Naumann, J. C., Anderson, J. E., \& Young, D. R. (2008). Linking physiological responses, chlorophyll fluorescence and hyperspectral imagery to detect salinity stress using the physiological reflectance index in the coastal shrub, Myrica cerifera. Remote Sensing of Environment, 112, 3865-3875.

Naumann, J. C., Young, D. R., \& Anderson, J. E. (2007). Linking leaf chlorophyll fluorescence properties to physiological responses for detection of salt and drought stress in coastal plant species. Physiologia Plantarum, 131, 422-433.
Naumann, J. C., Young, D. R., \& Anderson, J. E. (2008). Leaf fluorescence, reflectance, and physiological response of freshwater and saltwater flooding in the evergreen shrub, Myrica cerifera. Environmental and Experimental Botany, 63, 402-409.

Naumann, J. C., Young, D. R., \& Anderson, J. E. (2009). Spatial variations in salinity stress across a coastal landscape using vegetation indices derived from hyperspectral imagery. Plant Ecology, 202, 285-297.

Nestleroad, J., Zimmerman, D., \& Ebinger, J. (1987). Autumn olive reproduction in three Illinois state parks. Transactions of the Illinois Academy of Science, 80, 33-39.

Newbold, P. J. (1967) IBP Handbook No. 2: Methods for estimating the primary production of forests. International Biological Programme, London.

Nicola, A., \& Pickett, S. T. A. (1983). The adaptive architecture of shrub canopies: Leaf display and biomass allocation in relation to light environment. The New Phytologist, 93, 301-310.

Rouse, J. W., Haas, R. H., Schell, J. A., Deering, D. W., \& Harlan, J. C. (1974). Monitoring the vernal advancements and retrogradation of natural vegetation. NASA/GSFC, Final Report, Greenbelt, MD, USA (pp. 1-137).

Runyon, J., Waring, R. H., Goward, S. N., \& Welles, J. M. (1994). Environmental limits on net primary productivity and light use efficiency across the Oregon transect. Ecological Applications, 4, 226-237.

Sanchez-Azofeifa, G. A., Castro-Esau, K. L., Kurz, W. A., \& Joyce, A. (2009). Monitoring carbon stocks in the tropics and the remote sensing operational limitations: From global to regional projects. Ecological Applications, 19, 480-494.

Sands, P. J. (1995). Modeling canopy production 1: optimal distribution of photosynthetic resources. Australian Journal of Plant Physiology, 22, 593-601.

Šesták, Z. (1971). Determination of chlorophylls $a$ and $b$. In Z. Šesták, J. Čatský, \& P. G. Jarvis (Eds.), Plant photosynthetic production. Manual of methods (pp. 672-701). The Hague: Dr W. Junk N.V. Publishers.

Sturm, M., Schimel, J., Michaelson, G., Welker, J. M., Oberbauer, S. F., Liston, G. E., Fahnstock, J., \& Romanovsky, V. E. (2005). Winter biological processes could help convert Arctic tundra to shrubland. BioScience, 55, 17-26.

Turner, D. P., Ollinger, S. V., \& Kimball, J. S. (2004). Integrating remote sensing and ecosystem process models for landscape- to regional-scale analysis of the carbon cycle. Bioscience, 54, 573-584.

Wang, Q., Adiku, S., Tenhunen, J., \& Granier, A. (2005). On the relationship of NDVI with leaf area index in a deciduous forest site. Remote Sensing of Environment, 94, $244-255$.

Wessman, C. A., Archer, S., Johnson, L. C., \& Asner, G. P. (2004). Woodland expansion in US grasslands: Assessing land-cover change and biogeochemical impacts. In G. Guttman, A. Janetos, \& D. Skole (Eds.), Land change science: Observing, monitoring and understanding trajectories of change on the Earth's surface (pp. 185-208). New York, USA: Kluwer Academic Publishers.

Wilbur, R. L. (1994). The Myricaceae of the United States and Canada: Genera, subgenera, and series. Sida, 16, 93-107.

Young, D. R., Porter, J. H., Bachmann, C. H., Shao, G., Fusina, R. A., Bowles, J. H., et al. (2007). Cross-scale patterns in shrub thicket dynamics in the Virginia barrier complex. Ecosystems, 10, 854-863.

Zarco-Tejada, P. J., Berni, J. A. J., Súarez, L., Sepulcre-Cantó, G., Morales, F., \& Miller, J. R. (2009). Imaging chlorophyll fluorescence with an airborne narrow-band multispectral camera for vegetation stress detection. Remote Sensing of Environment, 113, $1262-1275$

Zarco-Tejada, P. J., Miller, J. R., Mohammed, G. H., Noland, T. L., \& Sampson, P. H. (2002), Vegetation stress detection through chlorophyll $a+b$ estimation and fluorescence effects on hyperspectral imagery. Journal of Environmental Quality, 31, 1433-1441.

Zhang, Y., Chen, J. M., Miller, J. R., \& Noland, T. L. (2008). Leaf chlorophyll content retrieval from airborne hyperspectral remote sensing imagery. Remote Sensing of Environment, 112, 3234-3247. 